DOI: https://doi.org/10.47405/mjssh.v7i1.1255

\begin{tabular}{|c|c|}
\hline 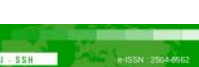 & Malaysian Journal of Social Sciences and Humanities (MJSSH) \\
\hline $\begin{array}{l}\text { Malaysian Journal of } \\
\text { Socai sciences and }\end{array}$ & Volume 7, Issue 1, January 2022 \\
\hline (MJ-sSH) & e-ISSN : 2504-8562 \\
\hline & $\begin{array}{l}\text { Journal home page: } \\
\text { www.msocialsciences.com }\end{array}$ \\
\hline
\end{tabular}

\title{
Kesediaan Menggunakan e-Pembelajaran dalam Melaksanakan Kursus Pendek di Kolej Komuniti Rompin Akibat Pandemik Covid-19
}

\author{
Mohd Zulfakar Bin Mohd Nawi' ${ }^{1}$, Abdul Majeed Bin Zulkipli' ${ }^{1}$, Abdul Rasid Bin Abdul Razzaq ${ }^{1}$ \\ 1Jabatan Ikhtisas Pendidikan, Fakulti Pendidikan Teknikal dan Vokasional, \\ Universiti Tun Hussein Onn Malaysia (UTHM), Malaysia \\ Correspondence: Mohd Zulfakar Mohd Nawi (hb200082@siswa.uthm.edu.my)
}

\begin{abstract}
Abstrak
Kajian ini dijalankan bertujuan bagi mengenal pasti keperluan latihan bagi para pensyarah di Kolej Komuniti Rompin terhadap Pembelajaran dan Pengajaran (PdP) bagi perlaksanaan kursus pendek secara dalam talian berbanding kaedah konvensional iaitu pembelajaran secara bersemuka. Maklumat diambil dalam bentuk kuantitatif dengan menggunakan kaedah secara tinjauan. Instrumen kajian menggunakan set soal selidik yang dibina menggunakan Google Form. Borang soal selidik ini mengandungi 4 soalan di bahagian A, 8 soalan di bahagian B dan 7 soalan di bahagian C. Penggunaan skala likert 5- mata diguna pakai bagi menjawab setiap soalan di bahagian B dan C. Seramai 36 pensyarah Kolej Komuniti Rompin telah dipilih sebagai sampel kajian dengan menggunakan pensampelan secara rawak. Kajian ini memfokuskan kepada (1) tahap pengetahuan pensyarah tentang pengajaran dan pembelajaran (PdP) kursus pendek secara dalam talian serta (2) tahap kesediaan pensyarah untuk mengajar kursus pendek secara dalam talian. Data yang diperolehi dianalisis bagi mendapatkan nilai peratus dan skor min menggunakan perisian Statistical Package for the Social Sciences (SPSS) versi 26.0. Secara keseluruhannya dapatan dan cadangan dari kajian ini diharap dapat membantu para pensyarah di KKRP untuk mengajar kursus pendek secara dalam talian sebagai medium pembelajaran di norma baru.
\end{abstract}

Kata kunci: pengajaran dalam talian, pensyarah, kursus pendek

\section{Readiness to Use e-Learning in Conducting Short Courses at Rompin Community College Due to the Covid-19 Pandemic}

\begin{abstract}
This study was conducted to identify the training needs of lecturers at Rompin Community College on Learning and Teaching (PdP) on e-learning for the short courses online compared to the conventional method of face-to-face learning. Information was obtained in quantitative form using a survey method. The research instrument used a set of questionnaires constructed using Google Form. This questionnaire contains 4 questions in section A, 8 questions in section B and 7 questions in section C. The use of a 5-point Likert scale was used to answer each question in sections B and C. A total of 36 Rompin Community College lecturers were selected as study samples using random sampling. This study focuses on (1) the level of knowledge of lecturers about teaching and learning (PdP) of short courses online as well as (2) the level of readiness of lecturers to teach short courses online. The data obtained were analyzed to obtain percentage values and mean scores using Statistical Package for the Social Sciences (SPSS) version 26.0. Overall, the findings and recommendations from this study are
\end{abstract}


expected to help the lecturers at Rompin Community College to use e-learning platforms to teach short courses as a medium of learning in the new norm.

Keywords: e-learning, lecturers, short courses

\section{Pengenalan}

Penggunaan internet serta telefon pintar sebagai medium pembelajaran dan pengajaran menjadi salah satu faktor transformasi dan pembaharuan yang ketara dalam sistem pendidikan di Malaysia. Pengajaran dalam talian kini adalah satu hala tuju baharu dalam pendidikan di negara ini selaras seperti mana dalam kehendak Kementerian Pendidikan Malaysia (KPM) untuk melaksanakan pembelajaran abad ke-21 (PAK-21) yang menerapkan penggunaan teknologi dalam proses pengajaran bermula pada tahun 2014. Pelaksanaan PAK-21 diharap mampu memenuhi keperluan pendidikan pada masa kini serta membawa perubahan baharu dalam dunia pendidikan. Seperti mana dalam Pelan Pembangunan Pendidikan Tinggi 2015-2025 oleh KPM, yang mengiktiraf penggunaan teknologi pembelajaran dalam usaha memperbaiki kebolehcapaian dan prestasi pelajar serta pengajar di Malaysia. Penggunaan kaedah pengajaran secara dalam talian ini juga turut mengubah kaedah pengajaran di dalam bidang Pendidikan Teknikal dan Latihan Vokasional (TVET) serta pengajar turut didedahkan dengan penggunaan teknologi serta maklumat baharu. Hasilnya banyak aplikasi pintar telah diwujudkan bagi membantu pengajar antaranya seperti Kahoot, Google Classroom, dan Google Meet, yang aplikasinya mudah serta sesuai diguna pakai untuk semua peranti pintar.

\section{Pernyataan Masalah}

Penutupan institusi pendidikan tinggi dan sekolah disebabkan oleh pandemik Covid-19 ini telah memberi kesan terhadap struktur Pembelajaran dan Pengajaran (PdP) iaitu daripada kaedah PdP secara langsung di institusi kepada PdP atas talian (PdPDT) secara sepenuhnya. Menerusi satu mesyuarat khas menteri-menteri mengenai Pelaksanaan Perintah Kawalan Pergerakan (PKP) Majlis Keselamatan Negara (MKN) pada 16 Mei 2020 telah meluluskan cadangan Kementerian Pengajian Tinggi (KPT) berkenaan pengendalian aktiviti akademik di kampus Institusi Pendidikan Tinggi (IPT) semasa dan pasca PKP. Menurut kenyataan pihak KPT bertarikh 27 Mei 2020 memaklumkan bahawa semua aktiviti PdP termasuklah kursus pendek hendaklah dilaksanakan secara atas talian sehingga 31 Disember 2020, serta semua aktiviti PdP dan pertemuan kursus pendek secara bersemuka adalah tidak dibenarkan. Justeru itu, bagi memastikan arahan KPT dipatuhi, Kolej Komuniti Rompin (KKRP) mengambil maklum dengan menangguhkan aktiviti PdP serta pelaksanaan kursus pendek buat seketika, Namun begitu, dengan permintaan dan keperluan bagi melaksanakan kursus pendek yang mendapat permintaan tinggi menyebabkan Unit Pendidikan Sepanjang Hayat (UPSH) mencadangkan pengajaran kursus pendek secara dalam talian. Kenyataan ini diperkuatkan lagi dengan edaran surat bertarikh 14 Januari 2021 oleh Jabatan Pendidikan politeknik dan Kolej Komuniti (JPPKK) yang mana satu garis panduan pengurusan operasi institusi pendidikan tinggi semasa dan pasca perintah kawalan pergerakan (PKP) 2.0 telah diedarkan yang melibatkan aspek PdP di mana negeri-negeri di bawah perintah kawalan bersyarat (PKPB) tidak dibenarkan melaksanakan aktiviti kursus pendek kecuali secara dalam talian (Unit PSH, Bahagian kurikulum JPKK, 2021). Ianya turut diperkukuhkan lagi dalam kenyataan media pada 11 Mei 2021 di mana telah menetapkan bahawa semua IPT di bawah kawal selia KPT perlu meneruskan PdPDT semasa tempoh pelaksanaan PKP bermula 12 Mei 2021 hingga 7 Jun 2021. Hal ini menjadi kejutan kepada pensyarah di KKRP yang merasa terbeban dengan pelaksanaan aktiviti pengajaran kursus pendek dalam talian secara sepenuhnya di samping aktiviti PdP bersama pelajar sedia ada. Kaedah PdPDT ini sangat mencabar keupayaan seseorang individu terutama para pengajar untuk melaksanakannya (B. Noraini, M. Yusuf \& J. Ahmad, 2020). Ianya diperkuatkan di dalam kajian oleh Azura, Suzana dan Zulkurnain (2021) yang menyatakan bahawa antara cabaran bagi pengajaran secara dalam talian adalah seperti capaian kepada kemudahan internet, tiada kemudahan komputer atau telefon pintar serta suasana pembelajaran yang tidak kondusif. Maka pengkaji mengambil inisiatif dengan melakukan satu kajian tinjauan untuk melihat sejauh mana pensyarah KKRP bersedia dalam 
Malaysian Journal of Social Sciences and Humanities (MJSSH), Volume 7, Issue 1, (page 31 - 39), 2022

DOI: https://doi.org/10.47405/mjssh.v7i1.1255

pelaksanaan kursus-kursus pendek secara dalam talian bagi melihat apakah keperluan latihan bagi memastikan aktiviti pengajaran kursus pendek dalam talian dapat dijalankan dengan baik.

\section{Objektif Kajian}

1. Mengukur tahap pengetahuan pensyarah tentang pengajaran kursus pendek secara dalam talian.

2. Mengukur tahap kesediaan pensyarah melaksanakan PdP bagi kursus pendek secara dalam talian.

3. Menentukan keperluan latihan bagi memastikan kursus pendek secara dalam talian dapat dilaksanakan dengan baik.

\section{Persoalan Kajian}

1. Apakah tahap pengetahuan pengajaran kursus pendek secara talian dalam kalangan pensyarah di KKRP?

2. Bagaimanakah tahap kesediaan pensyarah dalam melaksanakan kursus pendek secara PdPDT?

3. Apakah keperluan latihan bagi memastikan kursus pendek secara dalam talian dapat dilaksanakan dengan baik?

\section{Sorotan Kajian}

Pelaksanaan dasar hala tuju baru PSH telah diwar-warkan oleh JPPKK di semua Kolej Komuniti seluruh Malaysia. Ianya merangkumi 5 teras baharu di antaranya membangunkan komuniti yang celik digital seiring 4IR (Nota Jemaah Menteri Pencapaian 20 tahun PSH, KPT 17 Julai 2020). Justeru itu, dalam merealisasikan hala tuju baharu ini, tenaga pengajar didedahkan dengan penggunaan teknologiteknologi baru serta kepelbagaian evolusi teknologi pendidikan dicipta dan dibentuk.

Menurut pandangan Syed Ardi dan Zaidatun (2008) mengatakan penggunaan teknologi dalam bidang pendidikan tidak dapat dielakkan disebabkan kemajuan teknologi yang berkembang pesat. Ianya turut dibincangkan oleh Shuib, Sarkawi dan Yaakob (2020), persekitaran mobile learning telah dikenal pasti sebagai kaedah yang baru dan menarik serta mampu mengubah cara manusia belajar. Manakala dalam kajian yang dibuat oleh Baharuddin, Abu dan Ali (2001) menyatakan penggunaan teknologi media melalui pelbagai platform media seperti teks, grafik, audio, video dan animasi dapat memberikan satu hasilan persembahan maklumat yang lebih interaktif serta berkesan. Penyataan ini turut diperkuatkan dalam kajian yang ditulis oleh Saifuilnizan (2018), yang menegaskan penggunaan perisian atau aplikasi, perkakasan atau gajet sebagai peralatan teknologi pendidikan dalam proses PdP dapat meningkatkan keberkesanan dan kecekapan sesi pengajaran dan pemudahcaraan yang dijalankan. Menurut Kanuka dan Anderson (2007) serta Rana, Rajiv dan Lal (2014) pengajar boleh menjalankan aktiviti pengajaran secara segerak (synchronously) atau secara tidak segerak (asynchronously), meskipun terdapat sebahagian pensyarah dan pelajar pernah menggunakan aplikasi-aplikasi pembelajaran secara dalam talian, namun masih terdapat jurang serta cabaran besar dalam pelaksanaannya buat mereka.

\section{Metod Kajian}

\section{Reka Bentuk Kajian}

Kajian yang dilaksanakan adalah kajian deskriptif berbentuk tinjauan. Kajian ini dipilih berdasarkan kesesuaian dengan bentuk kajian yang dibuat kerana ia lebih praktikal dan realistik untuk mendapatkan maklum balas yang baik daripada responden. Kajian tinjauan ialah pengumpulan data secara terus daripada kumpulan subjek dengan menggunakan soalan kajian (soal selidik) melalui lisan atau kertaspensel (Chua, 2014). 


\section{Populasi dan Sampel Kajian}

Kajian ini dijalankan di Kolej Komuniti Rompin, Pahang. Populasi kajian adalah terdiri daripada 36 orang pensyarah daripada 40 pensyarah yang diambil secara rawak. Menurut Chua (2014) yang mengadaptasi dari kaedah penyelidikan dalam Krejcie dan Morgan (1970) adalah mencukupi dengan mengambil seramai 36 orang responden sebagai sampel bagi mewakili keseluruhan populasi kajian.

\section{Instrumen Kajian}

Kaedah kuantitatif melalui edaran borang selidik yang dibina menggunakan Google Form serta diedarkan melalui medium Telegram dipilih sebagai instrumen kajian. Ianya bertujuan untuk mendapatkan data kajian dalam masa yang singkat. Pembinaan borang soal selidik ini diadaptasi dan diubahsuai daripada kajian tinjauan yang dijalankan oleh Jawatankuasa Penyelaras Pembelajaran Digital JPKK (2020) yang bertajuk "Kesediaan Pensyarah Politeknik Dan Kolej Komuniti Terhadap Pengajaran Dan Pembelajaran Dalam Talian (PdPDT)". Borang soal selidik yang digunakan mengandungi tiga bahagian iaitu bahagian A, B, dan C. Setiap satu bahagian mewakili setiap pemboleh ubah yang dikaji. Bahagian A mengandungi 4 item untuk melihat demografi responden, Bahagian $\mathrm{B}$ mengandungi 8 item untuk mengukur aspek pengetahuan responden dan Bahagian $\mathrm{C}$ mengandungi 7 item untuk mengukur aspek kesediaan responden. Skala Likert 1 hingga 5 yang diadaptasi daripada Mohamad Majid (1998) seperti jadual 1 digunakan untuk mengukur maklum balas responden bagi setiap item yang dikemukakan.

\section{Kaedah Analisis}

Dapatan yang diperoleh dianalisis secara kuantitatif dengan menggunakan Statistical Package For Social Science (SPSS) versi 26.0 dengan menggunakan teknik seperti analisis kekerapan dan deskriptif. Analisis kekerapan dilakukan untuk mendapatkan data mengenai latar belakang responden seperti jantina dan umur. Analisis statistikal deskriptif digunakan bagi tujuan untuk mendapatkan skor min dan sisihan piawaian bagi aspek demografi, pengetahuan dan kesediaan. Penentuan interpretasi min adalah berdasarkan julat skor min sebagaimana diubahsuai daripada Creswell (2005).

\section{Hasil Kajian}

\section{Demografi Responden Kajian}

Bagi data demografi responden, kaedah statistik kekerapan digunakan. Ianya merangkumi jantina, umur, bidang mengajar serta pengalaman mengajar responden. Hasil analisis mengikut jenis data demografi responden diperbincangkan berdasarkan jadual 1, jadual 2, jadual 3 serta jadual 4.

Jadual 1: Profil responden mengikut jantina

\begin{tabular}{ccc}
\hline Jantina & Frekuensi & Peratus (\%) \\
\hline Lelaki & 26 & 72.2 \\
Perempuan & 10 & 27.8 \\
Jumlah & 36 & 100.0 \\
\hline
\end{tabular}

Berdasarkan jadual 1, data kajian menunjukkan bahawa responden kajian adalah terdiri daripada 36 orang responden. Jumlah responden lelaki adalah seramai 26 orang (72.2\%) dan bagi responden perempuan pula adalah seramai 10 orang $(27.8 \%)$.

Jadual 2: Profil responden mengikut umur

\begin{tabular}{ccc}
\hline Umur (Tahun) & Frekuensi & Peratus (\%) \\
\hline $25-29$ & 1 & 2.8 \\
$30-35$ & 9 & 24.3 \\
\hline
\end{tabular}



DOI: https://doi.org/10.47405/mjssh.v7i1.1255

\begin{tabular}{ccc}
\hline $36-39$ & 12 & 33.3 \\
$40-45$ & 12 & 33.3 \\
$46-49$ & 1 & 2.8 \\
50 dan ke atas & 1 & 2.8 \\
Jumlah & 36 & 100.00 \\
\hline
\end{tabular}

Berdasarkan jadual 2, data kajian menunjukkan kategori umur mengikut pecahan tahun iaitu di mana 1 responden $(2.8 \%)$ mewakili lingkungan umur 25 hingga 29 tahun, 9 responden $(24.3 \%)$ mewakili lingkungan umur 30 hingga 35 tahun, 12 responden (33.3\%) mewakili lingkungan umur 36 hingga 39 tahun, 12 orang $(33.3 \%)$ mewakili lingkungan umur 40 hingga 45 tahun 1 orang $(2.8 \%)$ adalah daripada lingkungan 46 hingga 49 tahun dan 1 orang (2.8\%) berumur 50 tahun ke atas.

Jadual 3: Profil responden mengikut bidang

\begin{tabular}{ccc}
\hline Program & Frekuensi & Peratus (\%) \\
\hline Kulinari & 9 & 25.0 \\
Automotif & 8 & 19.7 \\
Teknologi Elektrik & 7 & 19.2 \\
Penyamanan Udara & 5 & 16.7 \\
Operasi Perhotelan & 4 & 11.1 \\
Pengajian Am & 3 & 8.3 \\
Jumlah & 36 & 100.0 \\
\hline
\end{tabular}

Berdasarkan jadual 3, data kajian menunjukkan bahawa 9 responden $(25.0 \%)$ adalah pensyarah di dalam bidang Kulinari, 8 responden (19.7\%) dari bidang Automatif, 7 responden (19.2\%) dari bidang Teknologi Elektrik, 5 responden $(16.7 \%)$ dari bidang Penyamanan Udara, 4 responden $(11.1 \%)$ dari Operasi Perhotelan dan 3 responden (8.3\%) dari bidang Pengajian Am yang telah terlibat di dalam soal selidik kajian ini.

Jadual 4: Profil responden mengikut pengalaman mengajar

\begin{tabular}{ccc}
\hline Tahun Mengajar & Frekuensi & Peratus $(\%)$ \\
\hline $1-4$ tahun & 3 & 8.3 \\
$5-9$ tahun & 7 & 19.4 \\
$10-14$ tahun & 16 & 44.4 \\
15 tahun dan ke atas & 10 & 27.8 \\
Jumlah & 36 & 100.0 \\
\hline
\end{tabular}

Berdasarkan jadual 4, data kajian menunjukkan bahawa 3 responden (8.3\%) mempunyai 1 hingga 4 tahun pengalaman mengajar, 7 responden $(19.4 \%)$ pula mempunyai pengalaman mengajar sekitar 5 hingga 9 tahun, manakala seramai 16 responden (44.4\%) mempunyai 10 hingga 14 tahun pengalaman mengajar dan seramai 10 responden $(27.8 \%)$ mempunyai pengalaman mengajar melebihi 15 tahun ke atas.

\section{Analisis Aspek Pengetahuan}

Kaedah analisis deskriptif digunakan untuk mendapat nilai skor min dan sisihan piawai bagi aspek pengetahuan responden pada Bahagian B dan aspek kesediaan pada Bahagian C.

Jadual 5: Analisis aspek pengetahuan responden

\begin{tabular}{llccc}
\hline Bil & \multicolumn{1}{c}{ Item } & $\begin{array}{c}\text { Skor } \\
\text { Min }\end{array}$ & Sisihan Piawai & $\begin{array}{c}\text { Interpretasi } \\
\text { Min }\end{array}$ \\
\hline B1 & $\begin{array}{l}\text { Mempunyai pengetahuan dalam pelaksanaan } \\
\text { PdPDT }\end{array}$ & 3.69 & 0.889 & Memuaskan \\
B2 & \begin{tabular}{l} 
Bersedia melaksanakan PdPDT \\
\hline
\end{tabular} & 3.17 & 1.028 & Sederhana \\
\hline
\end{tabular}


DOI: https://doi.org/10.47405/mjssh.v7i1.1255

\begin{tabular}{|c|c|c|c|c|}
\hline B3 & $\begin{array}{l}\text { Mempunyai kemahiran di dalam PdPDT } \\
\text { (kemahiran menggunakan perisian aplikasi } \\
\text { komputer dalam pembelajaran digital, video } \\
\text { dsb) }\end{array}$ & 3.53 & 0.941 & Memuaskan \\
\hline B4 & $\begin{array}{l}\text { Pernah menggunakan PdPDT dalam } \\
\text { pengajaran saya }\end{array}$ & 3.89 & 0.979 & Memuaskan \\
\hline B5 & $\begin{array}{l}\text { Kandungan pengajaran saya boleh } \\
\text { dilaksanakan di dalam bentuk PdPDT }\end{array}$ & 2.69 & 1.117 & Sederhana \\
\hline B6 & $\begin{array}{l}\text { Penyampaian kandungan pengajaran saya } \\
\text { tidak sesuai untuk dilaksanakan secara } \\
\text { PdPDT. }\end{array}$ & 3.39 & 1.153 & Sederhana \\
\hline B7 & $\begin{array}{l}\text { Kandungan pengajaran saya boleh didapati } \\
\text { dalam bentuk digital daripada pelbagai } \\
\text { sumber. (cth:e-book, Digital Library, } \\
\text { YouTube dsb) }\end{array}$ & 3.25 & 1.079 & Sederhana \\
\hline B8 & $\begin{array}{l}\text { Saya yakin penyampaian kandungan } \\
\text { pengajaran secara PdPDT boleh mencapai } \\
\text { hasil pembelajaran kursus }\end{array}$ & 2.64 & 1.073 & Sederhana \\
\hline & Skor Min Keseluruhan & 2.80 & 0.749 & Sederhana \\
\hline
\end{tabular}

Berdasarkan dapatan analisis dalam jadual 5 bagi aspek pengetahuan responden (pensyarah), ianya menunjukkan tahap interpretasi min keseluruhan yang sederhana (skor min=2.80, sisihan piawaian 0.749). Dapatan memperlihatkan dalam aspek pengetahuan pensyarah bagi pengajaran secara dalam talian skor min tertinggi adalah pada item B4 (skor min $=3.89$, sisihan piawai 0.979) dengan interpretasi min Memuaskan. Diikuti dengan item B1 (skor min=3.69, sisihan piawai 0.889) dengan interpretasi min Memuaskan. Manakala item B3 (skor min=3.53, sisihan piawai 0.941) juga menunjukkan interpretasi min Memuaskan. Bagi item B8 ianya menunjukkan skor min terendah (skor min=2.64, sisihan piawai 1.073) dengan interpretasi min yang Sederhana. Diikuti dengan Item B5 (skor min=2.69, sisihan piawai=1.117) serta interpretasi min yang Sederhana. Begitu juga item B2 (skor min=3.17, sisihan piawai 1.028) ianya berada pada interpretasi min sederhana. Diikuti pula dengan item B7 (skor $\min =3.25$, sisihan piawai 1.079 ) yang berada pada interpretasi min Sederhana serta untuk item B6 (skor min=3.39, sisihan piawai 1.153) dengan interpretasi min Sederhana.

Jadual 6: Analisis aspek kesediaan responden

\begin{tabular}{|c|c|c|c|c|}
\hline Bil & Item & $\begin{array}{l}\text { Skor } \\
\text { Min }\end{array}$ & $\begin{array}{l}\text { Sisihan } \\
\text { Piawai }\end{array}$ & $\begin{array}{l}\text { Interpretasi } \\
\quad \text { Min }\end{array}$ \\
\hline $\mathrm{C} 1$ & $\begin{array}{l}\text { Saya mempunyai akses kepada komputer riba } \\
\text { yang berfungsi dengan baik. }\end{array}$ & 3.75 & 1.105 & Memuaskan \\
\hline $\mathrm{C} 2$ & $\begin{array}{l}\text { Capaian internet di rumah saya berupaya } \\
\text { menyokong pelaksanaan PdPDT. }\end{array}$ & 2.64 & 1.246 & Sederhana \\
\hline $\mathrm{C} 3$ & $\begin{array}{l}\text { Capaian internet di institusi saya berupaya } \\
\text { menyokong pelaksanaan PdPDT. }\end{array}$ & 3.89 & 0.950 & Memuaskan \\
\hline $\mathrm{C} 4$ & $\begin{array}{l}\text { Saya selalu menggunakan Learning } \\
\text { Management System (LMS) - CIDOS, } \\
\text { Microsoft Teams, Google Classroom }\end{array}$ & 3.42 & 1.105 & Memuaskan \\
\hline C5 & $\begin{array}{l}\text { Saya tahu bagaimana menggunakan Webex / } \\
\text { Microsoft Teams \& Google Classroom sebagai } \\
\text { aplikasi / platform PdPDT }\end{array}$ & 3.61 & 1.050 & Memuaskan \\
\hline C6 & $\begin{array}{l}\text { Infrastruktur ICT di institusi saya menyokong } \\
\text { perlaksanaan PdPDT }\end{array}$ & 3.67 & 0.828 & Memuaskan \\
\hline $\mathrm{C} 7$ & $\begin{array}{l}\text { Pembelajaran digital adalah sesuatu kebiasaan } \\
\text { dalam PdP saya }\end{array}$ & 2.94 & 1.068 & Sederhana \\
\hline & Skor Min Keseluruhan & 3.42 & 1.050 & Memuaskan \\
\hline
\end{tabular}


Berdasarkan dapatan analisis item yang dipaparkan pada jadual 6, nilai purata min bagi aspek tahap kesediaan responden (pensyarah) menunjukkan tahap interpretasi min keseluruhan yang memuaskan (skor $\min =3.42$, sisihan piawaian 1.050). Bagi aspek kesediaan pensyarah dalam pengajaran secara dalam talian, skor min tertinggi adalah pada item $\mathrm{C} 3$ (skor $\min =3.89$, sisihan piawai 0.950) dengan interpretasi min Memuaskan. Diikuti dengan item C1 (skor min=3.75, sisihan piawai 1.105) dengan interpretasi min Memuaskan. Manakala item C6 (skor $\min =3.67$, sisihan piawai 0.828) juga menunjukkan interpretasi min Memuaskan. Begitu juga dengan item C5 (skor min=3.61, sisihan piawai 1.050) yang menunjukkan interpretasi min Memuaskan serta item $C 4$ (skor min $=3.42$, sisihan piawai 1.105) juga menunjukkan interpretasi min yang Memuaskan. Bagi item C2 (skor min=2.64, sisihan piawai 1.246) menjadi skor min terendah dengan interpretasi min yang Sederhana. Diikuti dengan Item C7 (skor min=2.94, sisihan piawai=1.1068) serta interpretasi min yang Sederhana.

\section{Perbincangan}

Menerusi dapatan kajian dan analis yang telah dibuat, menunjukkan bahawa responden mempunyai tahap pengetahuan sederhana untuk melaksanakan kursus pendek secara PdPDT sebagai medium pembelajaran baharu di KKRP. Ianya menjawab persoalan kajian pertama yang mana interpretasi keseluruhan min menunjukkan dalam tahap sederhana. Meskipun dapatan item B4 yang menerima skor min tertinggi menjelaskan bahawa responden mengetahui serta pernah menggunakan PdPDT, namun masih terdapat beberapa halangan yang perlu dilihat serta dipertimbangkan bagi menjayakan PdPDT ini. Antaranya melalui dapatan tafsiran nilai min yang rendah bagi aspek pengetahuan bagi item B8 serta item B5 yang menunjukkan interpretasi min Sederhana. Pengkaji melihat terdapat halangan arahan yang dihadapi oleh responden dalam perlaksanaan PdPDT. Menurut Siti Azura et al (2021) halang arahan merujuk kepada tahap kualiti bahan pengajaran dalam talian, maklum balas daripada pelajar kepada pensyarah serta penerimaan arahan dan penerangan daripada pensyarah.

Manakala bagi persoalan kedua pula, dapatan kajian jelas menunjukkan bahawa responden bersedia untuk melaksanakan PdPDT dengan skor min tertinggi pada item C3 serta pada item C6 yang jelas menunjukkan pihak pengurusan KKRP amat bersedia untuk menjalankan PdPDT ini. Namun begitu masih terdapat kekangan yang perlu diatasi pada item $\mathrm{C} 2$ dan $\mathrm{C} 7$ yang mana menunjukkan interpretasi min sederhana. Halangan situasi merujuk kepada situasi atau persekitaran seseorang berada dalam melaksanakan sesuatu atau persekitaran seseorang itu berada. Antara bentuk halangan situasi termasuklah kesibukan dengan kerja, pengurusan masa kurang cekap dan gangguan daripada kerja lain (Schilke, 2001). Manakala halangan personaliti pula merujuk kepada persepsi kewujudan halanganhalangan disebabkan diri sendiri dan sikap terhadap E-pembelajaran (Siti Azura et al., 2021). Kenyataan ini diperkuatkan lagi dalam kajian oleh Mohd Koharuddin et al. (2003) yang menjelaskan bahawa masalah yang berkaitan dengan peribadi seseorang termasuk seperti tidak minat terhadap penggunaan aplikasi komputer, tidak selesa dengan ICT dan kekurangan kemudahan internet di tempat kediaman adalah merujuk kepada halangan personaliti.

Dapatan dari dua persoalan kajian yang pertama membantu untuk menjawab persoalan kajian yang ketiga. Keperluan latihan yang dikenal pasti adalah bagi mengukuhkan aspek pengetahuan para pensyarah dalam menjalankan kursus pendek secara dalam talian. Bahagian utama dalam aspek pengetahuan yang perlu diberi bimbingan adalah dari aspek kandungan pengajaran seperti dalam item B5. Oleh itu, pengkaji mencadangkan sebuah latihan dalam merancang reka bentuk kursus pendek secara dalam talian agar para pensyarah boleh memindahkan kandungan pengajaran yang selama ini disampaikan dalam bentuk bersemuka kepada bentuk dalam talian dengan berkesan. Item ini juga dilihat mempengaruhi item B8 di mana keyakinan para pensyarah akan lebih tinggi apabila mereka dapat merancang dengan baik bagaimana kandungan pengajaran itu boleh disampaikan secara dalam talian. 


\section{Kesimpulan}

Secara keseluruhannya, dapatan kajian ini diharapkan dapat menjadi titik permulaan kepada penambahbaikan sistem PdPDT bagi kursus pendek sedia ada selaras dengan perkembangan teknologi semasa. Dapatan kajian turut menunjukkan bahawa responden di KKRP mempunyai pengetahuan asas berkenaan konsep pembelajaran dalam talian, dan mempunyai tahap kesediaan yang tinggi untuk melaksanakannya. Hasil kajian penulis terdahulu juga jelas menunjukkan perlaksanaan PdPDT mampu memberikan impak positif serta menjadikan penggunaan aplikasi pendidikan sebagai salah satu medium pengajaran baharu. Oleh itu, dengan latihan yang sesuai pengetahuan dan kemampuan para pensyarah untuk melaksanakan kursus pendek secara dalam talian dalam dipertingkatkan sekaligus meningkatkan lagi keberkesanannya.

Justeru itu, hasil kajian ini diharapkan dapat membantu pihak pengurusan KKRP serta UPSH khususnya bagi mengambil kira keperluan meningkatkan bukan hanya kemahiran penggunaan teknologi maklumat dan komunikasi baharu yang diperlukan dalam melaksanakan transformasi kursus pendek malahan lebih utama lagi aspek kemahiran merancang dan memindahkan kandungan dari pembelajaran bersemuka kepada pembelajaran secara dalam talian. Ianya juga perlu menjadi titik permulaan yang positif kepada pensyarah KKRP khususnya serta komuniti luar amnya dalam memastikan kesinambungan pembelajaran sepanjang hayat dapat diteruskan dalam menyediakan peluang bagi generasi baharu dengan aktiviti pembelajaran dan komunikasi yang lebih baik tanpa mengambil kira faktor masa dan tempat pada era yang mencabar ini.

\section{Rujukan}

Baharuddin Aris, Mohd Salleh Abu \& Mohamad Bilal Ali (2001). Learning about information technology in education using multimedia. VirTEC Journal, 1(1).

Bibi Noraini Mohd Yusuf, \& Jihan Ahmad. 2020. "Are We Prepared Enough? A Case Study of Challenges in Online Learning in a Private Higher Learning Institution during the Covid-19 Outbreaks." Advances in Social Sciences Research Journal, 7(5):205-12

Chua Y. P. (2014). Kaedah Penyelidikan. Dalam Krejcie \& Morgan(1970). Menentukan Saiz Sampel dengan Mengawal Ralat Jenis 1(pp.237). Mc Graw Hill:Malaysia

Creswell, J. W. (2005). Educational research-planning, conducting and evaluating quantitative and qualitative research. Columbus: Pearson Merril Prentice Hall.

JPPKK (2018). Pelan Startegik Politeknik dan Kolej Komuniti 2018 - 2025 (47-55) Perpustakaan Negara Malaysia

Kanuka, Heather, \& Terry Anderson. (2007). Ethical Issues in Qualitative E-Learning Research. International Journal of Qualitative Methods, 6(2):1-14.

Mohd Koharuddin Mohd Balwi, Adanan Mat Junoh, et al. (2003). Kesediaan Pelajar University Malaysia Menggunakan E-Pembelajaran Sebagai Satu Alat Pembelajaran. Satu kajian kes di unisversiti Teknologi Malaysia (UTM) di Skudai.

Mohd Majid, K. (1998). Kaedah Penyelidikan Pendidikan. Kuala Lumpur: Dewan Bahasa dan Pustaka.

Rana, Hemant, Rajiv Rajiv, \& Manohar Lal. (2014). E-Learning: Issues and Challenges. International Journal of Computer Applications, 97(5):20-24.

Rod Sims, Graeme Dobs \& Tim Hand (2002). Enhancing Quality in Online Learning: Scaffolding Planning and Design Through Proactive Evaluation. Distance Education, 3(2), 135-148.

Saifuilnizan Che Ismail (2018), Majalah Pendidik; Guru \& Aplikasi ICT Dalam PdPc Abad 21

Schilke, R.A. (2001). A case study of attrition in web-based instruction for adults: Updating Garland's model of barriers to persistence in distance educational.

Shuib, A., Sarkawi, A., \& Yaakob, M. (2020). Pengaruh Pengalaman Teknologi, Peluang Dan Kesediaan Terhadap Penggunaan Mobile Learning Di Institut Pendidikan Guru Zon Utara. Jurnal Dedikasi, 14.

Siti Azura Binti Abu Hassan, Suzana Binti Zainol Abidin,\& Zulkurnain Bin Hassan (2021). Keberkesanan Pembelajaran Dan Pengajaran Dalam Talian E - Pembelajaran Terhadap Pembelajaran Pelajar Di Kolej Komuniti Hulu Langat. 
Malaysian Journal of Social Sciences and Humanities (MJSSH), Volume 7, Issue 1, (page 31 - 39), 2022

DOI: https://doi.org/10.47405/mjssh.v7i1.1255

Syed Ardi Syed Yahya Kamal, \& Zaidatun Tasir. (2010). Pembelajaran masa depan- mobile learning (m-learning) 